\title{
Aprendizaje matemático y tecnologías digitales: invenciones robóticas para el tratamiento de Parkinson
}

\author{
Greiton Toledo de Azevedo ${ }^{1}$ \\ greiton.azevedo@ifgoiano.edu.br \\ https://orcid.org/0000-0002-2681-1915 \\ Marcus Vinicius Maltempi ${ }^{2}$ \\ marcus.maltempi@unesp.br \\ https://orcid.org/0000-0001-5201-0348 \\ ${ }^{1}$ Instituto Federal Goiano (IF, Brasil) \\ ${ }^{2}$ Universidade Estadual Paulista (UNESP, Brasil)
}

Recibido: 15/04/2020 Aceptado: 04/07/2020

\begin{abstract}
Resumen
Nuestro objetivo es comprender el proceso creativo del aprendizaje matemático a lo largo de la producción del juego Navigation, asociado a un dispositivo robótico, para el tratamiento de 27 síntomas de la enfermedad de Parkinson. Guiada por una investigación cualitativa, la producción de datos 28 se realizó con estudiantes de secundaria de IFGoiano, Ipameri - GO. El escenario formativo 29 de la investigación se creó como un lugar para construir / proponer soluciones a problemas reales, basados en las matemáticas y la robótica a favor de la sociedad, de manera que las carreras científicas y tecnológicas 31 sean uno de los posibles proyectos de vida e investigación. transformación social, intelectual 32 y científica de los estudiantes. Para ello, ponemos en la agenda discusiónanálisis del desarrollo científico-tecnológico, colaborativo-argumentativo e inventivocreativo de tecnologías, yendo más allá de los muros del aula de matemáticas. Planteamos análisis-reflexiones sobre el proceso 35 de convertirse en pensador creativo en matemáticas a expensas de la reproducción de conceptos y 36 mecanismos pedagógicos que no se justifican. Por tanto, basamos nuestras acciones en la Teoría 37 del Aprendizaje Creativo y la Insubordinación Creativa. Concluimos que el proceso creativo 38 del aprendizaje matemático se muestra dinámico y fluido, consistente en pasos no lineales 39 y se ve reforzado por elementos inherentes al proceso formativo, entre los que destacan los siguientes: 40 curiosidad, imaginación, argumentación e invención.
\end{abstract}

Palabras clave: Enseñanza de las matemáticas; Juegos digitales; Robótica; El tratamiento de Parkinson

\section{Aprendizagem matemática e tecnologias digitais: invenções robóticas para o tratamento de Parkinson}

\section{Resumo}

Nosso objetivo é compreender o processo criativo de aprendizagem matemática ao longo da produção do jogo Navegação, associado a dispositivo robótico, destinado ao tratamento de sintomas da doença de Parkinson. Norteados pela pesquisa qualitativa, a produção de dados foi realizada com alunos do Ensino Médio do IF-Goiano, Ipameri - GO. O cenário formativo da pesquisa foi criado como lugar para construir/propor soluções para problemas reais, a partir da matemática e da robótica em favor da sociedade, de modo que 
as carreiras científicas e tecnológicas sejam um dos possíveis projetos de vida e de transformação social, intelectual e científica dos alunos. Para isso, colocamos em pauta discussão-análises do desenvolvimento científico-tecnológico, colaborativo-argumentativo e inventivo-criativo de tecnologias, indo além dos muros da sala de aula de matemática. Suscitamos análise-reflexões sobre o processo de se tornar pensador criativo em matemática em detrimento da reprodução de conceitos e mecanismos pedagógicos que não se justificam. Para tanto, baseamos nossas ações na Teoria de Aprendizagem Criativa e na Insubordinação Criativa. Concluímos que o processo criativo de aprendizagem matemática se mostra dinâmico e fluído, constituído por passos não lineares e se fortalece por elementos inerentes ao processo formativo, entre os quais se destacam: curiosidade, imaginação, argumentação e invenção.

Palavras-Chave: Ensino de Matemática; Jogos Digitais; Robótica; Tratamento de Parkinson.

\title{
Math learning and digital technologies: robotic inventions for the treatment for Parkinson
}

\begin{abstract}
Our goal is to understand the creative process of mathematical learning throughout the production of the Navigation game, associated with a robotic device, intended for the treatment of Parkinson's disease symptoms. Guided by qualitative research, data production was carried out with high school students from the IF IF-Goiano, Ipameri GO. The formative research scenario was created as a place to build / propose solutions to real problems from mathematics and robotics in favor of society, so that scientific and technological careers are one of the possible projects of life and the social, intellectual and scientific transformation of the students. For this, we discuss the analysis of scientifictechnological, collaborative-argumentative and inventive-creative development of technologies, going beyond the walls of the mathematics classroom. We raise analysisreflections on the process of becoming a creative thinker in mathematics at the expense of the reproduction of pedagogical concepts and mechanisms that are not justified. To do so, we base our actions on Creative Learning Theory and Creative Insubordination. We conclude that the creative process of mathematical learning is shown to be dynamic and fluid, consisting of non-linear steps, and is strengthened by elements inherent to the formative process, among which stand out: curiosity, imagination, argumentation and invention.
\end{abstract}

Key words: Mathematical teaching; Digital games; Robotics; Parkinson's treatment.

\section{Palavras iniciais}

Reconhecemos e admiramos os desenhistas, arquitetos, músicos e poetas por sua criatividade. Há muitas pessoas e profissionais no anonimato, que também são criativas na sua forma de encarar a vida (Resnick, 2017). Os cientistas podem ser criativos quando desenvolvem vacinas para problemas pandêmicos em nível planetário. Os médicos podem ser criativos ao diagnosticar doenças e desenvolver alternativas para o seu tratamento. Ao desenvolver startups sustentáveis, pensando no futuro das próximas gerações, os 
empreendedores se mostram criativos. Belos jardins certamente tiveram um toque de criatividade dado pelos jardineiros. Não diferente disso, a escola pode formar pensadores criativos quando propõe processos de invenção/aprendizagem ao aluno, orientando-o a lidar com imprevistos, tomar decisões conscientemente, criar soluções para os problemas, desenvolver ideias e conhecimentos científico-tecnológicos em favor das pessoas ao redor do mundo (Azevedo \& Maltempi, 2018; Azevedo et al., 2019; Papert, 2008; Resnick, 2017).

Partimos do princípio que é possível apoiar ideias criativas e construir cenários formativos à sociedade, tendo como base a criatividade aliada aos processos de ensino e aprendizagem de matemática. O processo criativo é dinâmico e carrega características inerentes à imaginação, curiosidade, argumentação e invenção de artefatos, que possam ser aplicadas em soluções de problemas atuais da sociedade (Resnick, 2017). Assim sendo, compreendemos que a criatividade deve ser cultivada nas aulas de matemática, configurando-se no campo abstrato da criação e no desenvolvimento de ideias e materiais, auxiliando os estudantes a desenvolverem-se enquanto sujeitos capazes de propor soluções reais baseadas em seus conhecimentos científicos e interesses pessoais (Azevedo, 2017; Papert, 2008).

Nessa perspectiva, buscamos compreender o processo criativo de aprendizagem em matemática ao longo da produção do jogo Navegação, associado a dispositivo robótico Timão, destinado ao tratamento de sintomas da doença de Parkinson. Tal busca pauta-se nas ideias da Aprendizagem Criativa (Resnick, 2017; Papert, 2008) e da Insubordinação Criativa (D’Ambrosio \& Lopes, 2015), que se apresentam em harmonia com as ideias construcionistas para a Educação (Papert, 2008). Norteados pela pesquisa qualitativa, a produção de dados foi realizada com alunos do Ensino Médio do IF-Goiano, Ipameri - GO, no cenário de formação/pesquisa do Projeto Mattics. Tal cenário é entendido como lugar para vivenciar experiências científico-tecnológicas e criativas, além de fomentar o desenvolvimento formativo, colaborativo e intelectual do aluno. Assim, tecemos resultados sobre o processo criativo de aprendizagem dos alunos, a partir dos cenários contextuais marcados por invenções e discursos dos pesquisados.

\section{Processo criativo de aprendizagem Matemática}

[...] olharam para os pássaros com o mesmo espírito que quero olhar para os exemplos de aprendizagem bem-sucedida. Contudo, não foi suficiente simplesmente observar e copiar que tomaram o caminho errado ao pensar que a essência do voo dos pássaros era o de bater 
das asas. Os pássaros podem voar sem bater as asas! Devemos aprender a ver a aprendizagem bem-sucedida pelo prisma dessas ideias poderosas. (Papert, 2008, p. 40).

As ideias de Seymour Papert (2008) nos encorajam a mobilizar práticas que valorizem o voo dos alunos, centrando nossos olhares no processo criativo de aprendizagem matemática e incentivando os sonhos e a invenção de dispositivos que sejam capazes de contribuir para um mundo melhor, além da sala de aula. Entendemos que essas práticas são mais favoráveis ao aprendizado do que a cópia nas aulas de matemática e, em especial, "experimentos ritualísticos da escola, pois pelo menos os aprendizes estarão engajados em uma atividade significativa e socialmente importante, sobre a qual eles concretamente se sentem responsáveis" (Papert, 2008, p. 38). Entendemos que não se pode ensinar criatividade, pois isso descaracterizaria a essência de pensar, desenvolver e inventar criativamente usando os conhecimentos curriculares de matemática. No entanto, é possível estimulá-la nos mais diferentes contextos de aprendizagem matemática, pois os alunos nascem com a capacidade de serem criativos, não obstante, a sua criatividade não necessariamente se desenvolverá sozinha. Dessa forma, suas necessidades devem ser nutridas, encorajadas e apoiadas (Resnick, 2017; Papert, 2008).

Assim, nosso entendimento não é o de ensinar criatividade nas aulas de Matemática, mas de incentivá-la ao longo do processo formativo sem deixar de lado a essência de imaginar e inventar criativamente. Na literatura encontramos contribuições para a discussão do processo de criatividade no contexto cognitivo, motivacional e cultural (Nakamura \& Csikszentmihalyi, 2003; Gotijo, 2007). Neste trabalho atentamos nosso olhar para o processo criativo de aprendizagem matemática como algo dinâmico-inventivo, caracterizado pela imaginação, originalidade e criação-produção de artefatos curiosos que não obedecem necessariamente a uma lógica linear de aprendizagem e regada de formalismos (Resnick, 2017; Azevedo et al., 2019). Em harmonia e corroborando esse entendimento, nos apoiamos na Insubordinação Criativa (D’Ambrosio \& Lopes, 2015) para construir e vivenciar um ambiente de aprendizagem que vai além dos testes padronizados e que possibilite ao aluno ter formação ativa, contextual e menos fragmentada no que se refere ao conteúdo.

Nesse sentido, nossa intenção é encorajar a criatividade durante o processo de produção de jogos digitais e dispositivos robóticos para o tratamento de sintomas da doença de Parkinson nas aulas de matemática. O processo é como “(...) o de um agricultor ou jardineiro cuidando das plantas, criando um ambiente no qual as plantas florescerão. Da 
mesma forma, você pode criar um ambiente de aprendizado no qual a criatividade floresça” (Resnick, 2017, p. 21-22, tradução nossa). Seguindo essa visão, assumimos que o processo criativo de aprendizagem matemática diz respeito à capacidade de o aluno poder comunicar ideias, verbalizar conhecimentos científicos, nutrir invenções e propor soluções para problemas da sociedade (Resnick, 2017; Papert, 2008; Maltempi, 2012).

Tal processo, ao desenvolver tecnologias em prol do outro, é visto como orgânico, coletivo e interativo (Azevedo et al., 2019), que incentiva a assunção do aluno enquanto ser pensante, inventor, comunicante, transformador e realizador de ideias poderosas (D’Ambrosio \& Lopes, 2015; Freire, 2005). E é justamente isso que, ao incentivar o processo criativo de matemática, estamos fazendo: provocando uma formação que não se reduz a testes padronizados, mas que incentiva os alunos a alcançarem seu potencial máximo, desenvolvendo invenções científico-tecnológicas voltadas ao bem-estar humano.

\section{O nosso contexto e a nossa travessia metodológica}

Visando atingir nosso objetivo de compreender o processo criativo de aprendizagem de matemática adotamos os pressupostos qualitativos de pesquisa, pois esta abordagem busca "atingir aspectos humanos sem passar pelos crivos da mensuração, sem partir de métodos previamente definidos e, portanto, sem ficar presos a quantificadores e aos cálculos recorrentes" (Bicudo, 2006, p. 107). Dessa forma, negamos a neutralidade do pesquisador durante o processo investigativo e consideramos que há sempre um aspecto subjetivo a ser considerado (Triviños, 2009; Bogdan \& Biklen, 1994).

A pesquisa foi realizada com a participação de 25 alunos do Ensino Médio do IFGoiano, Ipameri (GO).. Neste artigo trazemos para a discussão-análise distintas etapas da produção do jogo Navegação e do dispositivo robótico Timão em sala de aula, e a utilização de tais eletrônicos no tratamento da doença de Parkinson no Hospital Dia do Idoso, Anápolis - GO, relacionados à postura do paciente, estímulo à concentração e ao raciocínio lógico, além de movimentos circulares e coordenados que utilizam os braços e as mãos. Embora a doença não tenha cura, os sintomas podem ser retardados de modo a trazer qualidade de vida ao paciente, e uma das atividades do projeto é desenvolver jogos para auxiliar no tratamento de sintomas específicos da doença, contribuindo com a redução das limitações funcionais causadas pela rigidez, lentidão dos movimentos e alterações posturais, manutenção das amplitudes de movimento, prevenindo deformidades, incentivando o equilíbrio, marcha e coordenação; incentivo ao autocuidado e motivação. 
Tendo em vista os fatores da doença de Parkinson associados à degeneração das capacidades motoras e mentais, os dispositivos robóticos e jogos digitais produzidos na pesquisa pelos alunos, são usados na interação com os pacientes, que são encorajados a mexer, dançar, pular, concentrar, analisar eventos e refutar informações não condizentes com o objetivo de cada jogo.

A partir desta proposta de pesquisa, evidenciamos o processo criativo de aprendizagem dos alunos a partir de cenários contextuais marcados por transcrições e discursos dos pesquisados. Tais cenários são sequenciais e dialógicos e foram analisados à luz do aporte teórico estabelecido. Para registro dos dados utilizamos diversos instrumentos, como diário de campo do pesquisador, fotografias, filmagens e depoimentos dos alunos. Para a produção dos jogos foram utilizados os software ${ }^{l}$ Scratch e GeoGebra, $e$ a placa ${ }^{2}$ BBC Micro: bit. O Scratch é um ambiente de programação baseado em blocos que se encaixam e foi desenvolvido pelo grupo Lifelong Kindergarden do MIT. O GeoGebra é um software de matemática dinâmica, que abrange todos os níveis de ensino e combina diferentes vertentes da matemática, como geometria, álgebra, estatística e probabilidade. $O$ Micro: bit é considerado um pequeno computador com grandes potencialidades. Seus sensores detectam movimento, luz, temperatura e magnetismo. Para a apresentação e análise dos dados da pesquisa, utilizaremos recortes dos diálogos e discussões gravados e anotados, bem como faremos uso dos símbolos [ ] para explicitar trecho que se refira à transcrição de fala dos sujeitos. Ainda, utilizaremos os símbolos ( ) para supressão dos diálogos e contextualização.

Todos os participantes da pesquisa receberam os termos de consentimento/autorização e manifestaram interesse em participar sem o anonimato de suas identidades. Salienta-se que o trabalho foi aprovado no Comitê de Ética (CEP) da Universidade Estadual Paulista (Unesp).

\section{Apresentação e análise de dados}

Apresentamos e analisamos, nesta seção, o processo de aprendizagem criativa em matemática a partir do desenvolvimento do jogo Navegação ${ }^{3}$ e seu dispositivo robótico

1 Scratch (https://scratch.mit.edu/); GeoGebra (https://www.geogebra.org/);

2 Micro: bit (https://microbit.org/).

3 Uma roda de sucata de bicicleta se transforma em timão e paletes de madeira viram espaço de um navio da idade média. Com matemática e criatividade, movimentos de pássaros se transformam em curvas 
Timão, que alia ideias de programação e matemática (em especial, funções logarítmicas). A fim de explicitar o contexto formativo, destacamos abaixo as três principais etapas de aprendizagem.

Figura 1: Jogo Navegação: diferentes etapas da produção do Jogo (dados da pesquisa)
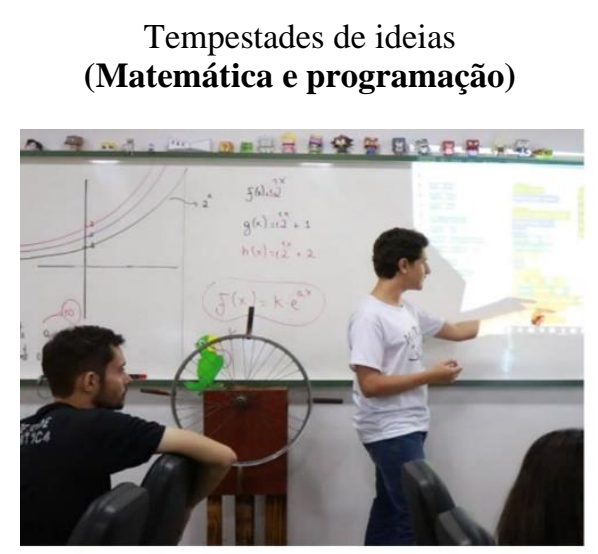

Timão-robótico visto de frente

(Materiais de baixo custo)

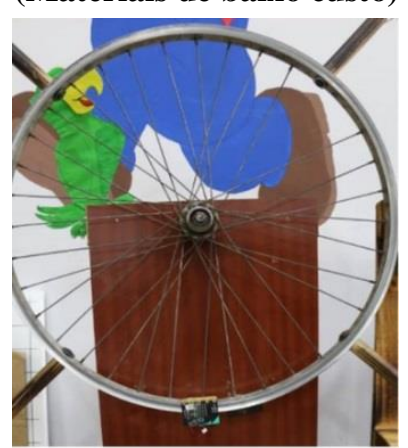

Aprimoramentos (simulações e feedback)

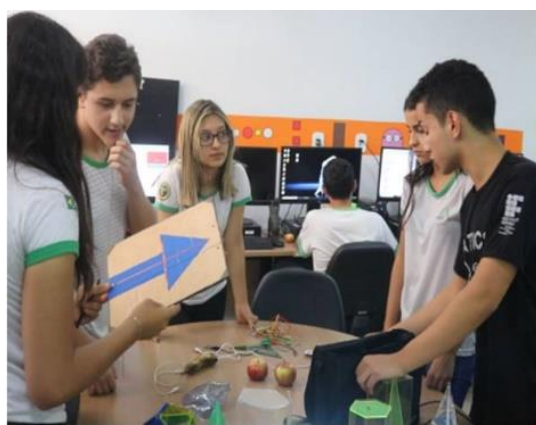

Fonte: Dados da pesquisa (2019)

A primeira imagem, mais à esquerda da Figura 1, exemplifica a argumentaçãoprodução coletiva e reflexões-criativas entre os alunos, que debatem e desenvolvem engenhocas de baixo custo, usando os conhecimentos de matemática, robótica e programação. $\mathrm{Na}$ imagem central, observamos o dispositivo robótico de baixo custo (Timão), que foi desenvolvido pelos alunos, utilizando placa BBC: micro-bit, paletes e uma roda de bicicleta. Por fim, a imagem à direita exemplifica a organização e avaliação dos materiais dos alunos, na semana que antecedeu à sessão de tratamento, no Hospital Dia do Idoso.

As etapas são complementares e dialógicas e todo conhecimento científico e técnico mobilizado, no espaço formativo do Mattics, destina-se a favor das pessoas, buscando soluções para movimentos específicos e estrategicamente coordenados no tratamento de sintomas da doença de Parkinson de pacientes/idosos. Por trás dos jogos e dos dispositivos robóticos, há ideias de matemática e conceitos de programação, como se observa no Quadro 1.

logarítmicas, enquanto trajetórias dos peixes são descritas em funções quadráticas. Essas ideias podem ser vistas em: $\quad$ https://www.youtube.com/watch?v=15gEq8NC16s\&list=UUi50Ir9b1$\underline{\text { 8ZzGAbi26TxCw\&index }=21}>$. 
Quadro 1: Por trás do jogo Navegação: ideias matemáticas e conceitos de programação

\begin{tabular}{|c|c|}
\hline Leiaute e algoritmos & Matemática e Programação \\
\hline PONTOS COC & $\begin{array}{l}\text { O palco [frame] é baseado no plano cartesiano de } \\
\text { dimensões }(x, y):-240 \leq x \leq 240 \text { e } 180 \leq y \leq 180 \text {. Há } \\
\text { também a presença de variáveis declaráveis, entre as } \\
\text { quais se destacam: Pontos e Tempo. As nuvens } \\
\text { carregam ideias de deslocamento, velocidade e } \\
\text { ampliação/redução, que ganham vida através dos } \\
\text { algoritmos construídos pelos alunos, usando ideias de } \\
\text { matemática e programação, como: (in)equações e } \\
\text { porcentagem, laços de repetição, condicionais, } \\
\text { controles e sensores. Há um leme de navio no centro } \\
\text { inferior. Este personagem sinaliza os movimentos } \\
\text { conectados ao BBC Micro: bit, que é o sensor de } \\
\text { movimentos do Timão do jogo, formado pela roda de } \\
\text { bicicleta e paletes estruturados. }\end{array}$ \\
\hline 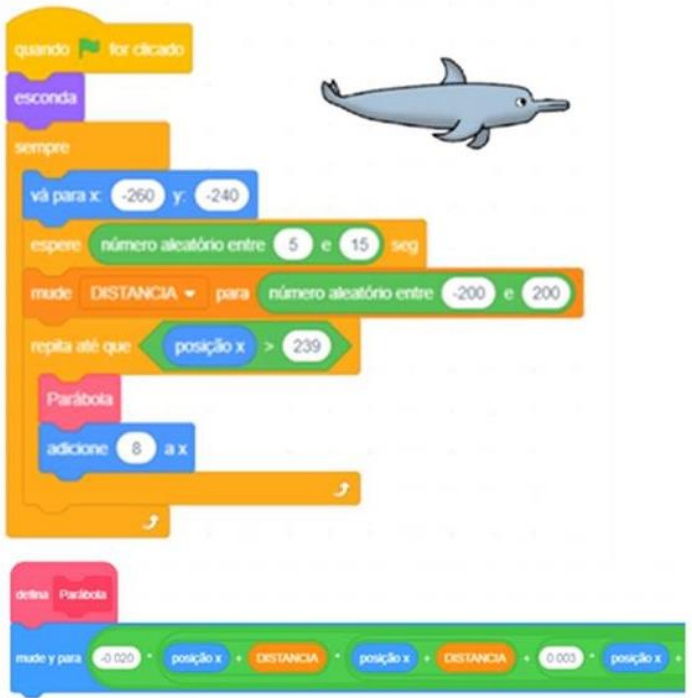 & $\begin{array}{l}\text { O programa é parte do movimento do golfinho no jogo, } \\
\text { iniciado por um controle que faz o personagem aparecer } \\
\text { e desaparecer em circuito constante e aleatório. Usa-se o } \\
\text { sistema de localização }(x, y) \text { integrado com comandos de } \\
\text { repetição [loop] e condicionais [repita até]. Faz uso de } \\
\text { conceitos de inequação [posição x }>239 \text { ], referindo-se a } \\
\text { posição do golfinho, no intervalo de confiança definido } \\
\text { aleatoriamente }[-200<x<200 \text { ] do jogo, tendo como } \\
\text { deslocamento o formato de parábolas com parâmetro [a, } \\
b \text { e } c \text { ] distintos. O grupo de alunos faz uso de sistema de } \\
\text { paralelismo de modo a sincronizar a estrutura com o } \\
\text { formato de parábola [parte do algoritmo] com } \\
\text { concavidade voltada para baixo a }<0 \text { [-0,020* } x+\boldsymbol{d}) *(x \\
+\boldsymbol{d})+0,003 *(x+c) \text { ], sendo } c:-180<c<180, b=0 e \\
a=-0,020, x: \text { variável, } d: \text { distância. Articula-se ideias } \\
\text { matemáticas com programação, baseado na lógica e } \\
\text { operacionalidade. }\end{array}$ \\
\hline
\end{tabular}

Fonte: dados da pesquisa (2019)

No Quadro 1, observamos os conteúdos de matemática e de programação mobilizados de forma integrada na composição de algoritmos do jogo. A produção desses algoritmos se baseia em uma visão não isolada do conhecimento e, ao mesmo tempo, reconhece que ele não é apenas a coleção de símbolos ou conceitos (Papert, 2008). À medida que os estudantes se engajam nessa produção, desenvolvem teias conceituais e procedimentais de matemática e programação, bem como comunicam ideias coletivamente. Nesse tocante, em forma de recorte, trazemos a imagem do leiaute do pássaro e, em seguida, destacamos a discussão-reflexão (brainstorming) (Papert, 2008) da construção do algoritmo desse personagem, evidenciando as ideias de matemática mobilizadas entre os alunos e o professor. 
Figura 2: Jogo Navegação: Movimento do Pássaro no jogo (design gráfico)

Leiaute e estrutura de movimento do pássaro no jogo: trajetória vinculada à curva logarítmica

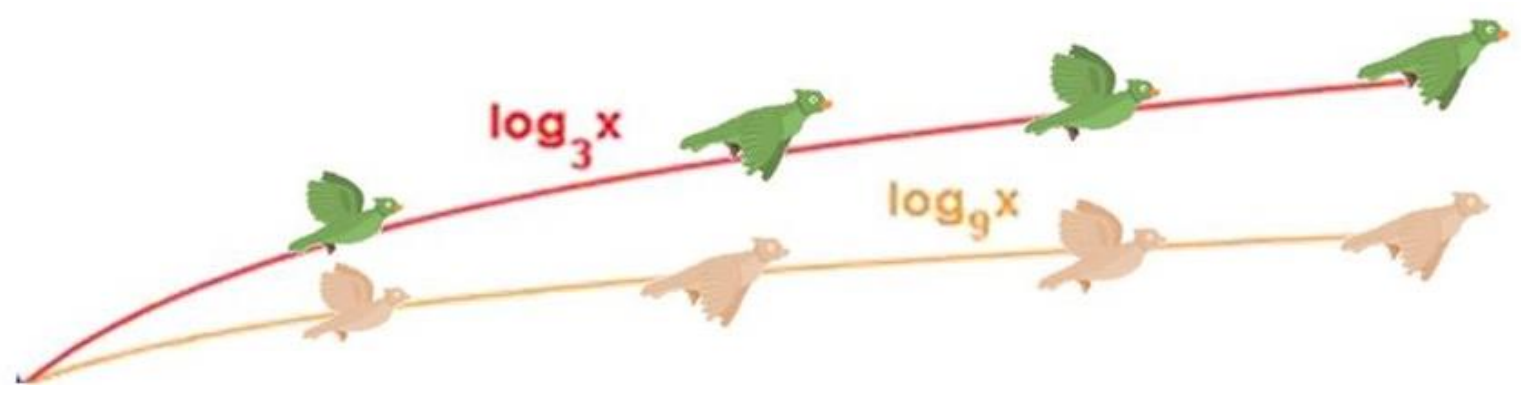

Fonte: Dados da Pesquisa (2019)

Eduardo: Ao pensar em vários caminhos com o meu grupo, percebemos que a trajetória descrita pela função exponencial não atenderia ao nosso projeto. $O$ pássaro extrapolaria as dimensões do palco [mostra o movimento] (...) Com a ajuda do professor, começamos a rascunhar o movimento do pássaro [no quadro branco e softwares: GeoGebra e Scratch] e criar ideias com a função logarítmica (...)

Caio: $\quad$ Como você mostrou aí no gráfico [Eduardo]... O movimento do pássaro se espelha igualmente a uma linha imaginária [assíntota], não é isso?

Eduardo: (...) Bem legal isso, né? Há simetria! Vimos também que, na trajetória do pássaro, a função logarítmica cresce lentamente, enquanto a função exponencial é bem rápida. Testamos valores e visualizamos diferentes resultados ao desenvolver o código [Mostra no Scratch as funções e suas inversas respectivas $\mathrm{f}(\mathrm{x})=3^{\mathrm{x}}$ e $\mathrm{g}(\mathrm{x})=\log _{3} \mathrm{x} ; \mathrm{h}(\mathrm{x})=9^{\mathrm{x}}$ e $\mathrm{y}(\mathrm{x})=\log _{9} \mathrm{x}$; etc.].

Professor: Excelente! Graficamente, a função logarítmica é representada de forma simétrica em relação à bissetriz dos quadrantes I e III. Testamos valores para $x>0$. Certo? Outra questão importante é analisarmos em conjunto: a curva do pássaro não toca o eixo y, mas corta o eixo x no ponto de abscissa igual a 1? Por quê? [discussão-reflexão sobre $\mathrm{y}=\log _{\mathrm{a}} 1=0$, para quaisquer valores de a].

Eduardo: Pensei que não conseguiríamos fazer o pássaro aparecer na tela inicial do jogo quando saltasse do navio em movimento, [mas] conseguimos! Então, criamos os movimentos do pássaro e alinhamos com os valores da base para dar mais propósito ao jogo e estimular movimentos do jogador [paciente]. Depois de verificar essas ideias, vimos que era necessário usar só valores maiores que 1 para base [a $>1]$, porque a curva tinha que crescer $\left[\mathrm{x}_{1}<\mathrm{x}_{2} \Leftrightarrow\right.$ $\left.\log _{\mathrm{a}} \mathrm{x}_{1}<\log _{\mathrm{a}} \mathrm{x}_{2}\right]$.

Líria: $\quad$ Então, se for positivo os valores da base, temos a garantia disso? [crescente]

Caio: $\quad$ Não, precisa ser maior que 1 [ a > 1], se estiver entre 0 e 1 , não vai dar certo, porque se $a=1 / 2$, a curva decresce [mostra movimentos do pássaro na tela] ...

Líria: $\quad$ Caracas! Finalmente, consegui entender isso! Sentindo-me até bem com isso!

À luz do excerto, observamos que os alunos comunicam ideias conjuntamente quando programam o movimento do pássaro, privilegiando conexões entre ideias matemática e lógica de programação. Ao analisar a fala do estudante Eduardo, "[pensamos] em vários caminhos [e] começamos a rascunhar [e a] criar ideias com a função logarítmica", entendemos que o foco não se limita ao conteúdo linear de matemática, mas na forma como os alunos o relacionam ao inventar personagens e criar 
seus movimentos por meio de algoritmos. Tal compreensão se reforça no questionamento/constatação gráfica da função logarítmica pelo aluno Caio, “[...] o movimento do pássaro se espelha igualmente a uma linha imaginária [assíntota], não é isso?!”. Tais alunos propõem ideias, descrevem teorias provisórias e constatam significados múltiplos ao buscar compreender o comportamento do voo do pássaro pela descrição logarítmica. O processo de produção se baseia na discussão-reflexão ao definir o funcionamento do algoritmo em grupo. É um processo "de aprendizagem no qual tanto os alunos como o professor interpretam o seu meio, levantam hipóteses, analisam contextos e constroem junto-engajadamente ideias e o conhecimento mobilizado" (Azevedo \& Maltempi, 2019, p.103).

O conhecimento não é transferido aos alunos pelo professor, mas mobilizado no coletivo e se fortalece pela busca não linear de significados entre professor-aluno e alunoaluno (Papert, 2008). A busca pelo significado de conceitos matemáticos durante a produção do algoritmo do pássaro é um processo dinâmico de conexões de ideias, não necessariamente previsível e controlado. O caminho favorece a compreensão do conteúdo de matemática pela discussão-argumentação e produção criativa, pois busca “(...) incentivar os alunos a: aprender, curiosidade sobre a ciência; capacidade de se envolver; tenacidade para pensar grande; [construir soluções]; ter persistência para fazer e resolver coisas incríveis [à sociedade]" (Resnick, 2017, p.51-52, tradução nossa).

Embora o pássaro não tenha um papel diretamente ligado aos movimentos coordenados do corpo do paciente de Parkinson pelo Timão, o grupo buscou criá-lo a fim de estimular a concentração, a visão e o raciocínio do jogador, como se observa nos seguintes discursos: "Pensei que não conseguiríamos fazer o pássaro aparecer na tela inicial (...) conseguimos!” e “(...) criamos os movimentos do pássaro e alinhamos com os valores da base da função [logarítmica] para dar mais propósito ao jogo e estimular a movimentos [específicos] do jogador”. Inferimos, nesse recorte, que há finalidade maior de aprendizagem, que alia o conhecimento curricular de matemática com a produção de eletrônicos ao tratamento de sintomas específicos da doença de Parkinson, valorizando a posição do estudante enquanto pesquisador dentro de sala em vez de reprodutor, dando mais sentido e contexto à matemática.

Mais do que mobilizar contexto ao ensino de matemática, percebemos que a sensação de incapacidade, quando o aluno é incentivado a argumentar e compreender o conteúdo e a lógica de programação, é deixada de lado e se transforma em 
significado/motivação, como se pode constatar na discussão entre Caio e Líria ao dialogar sobre o crescimento e decrescimento do pássaro à luz da função logarítmica, respectivamente: “(...) se estiver entre 0 e 1 , não vai dar certo, porque se $a=1 / 2$, a curva decresce”, [e] “(...) Caracas! Finalmente, consegui entender isso! Sentindo-me até bem com isso!". Entendemos que o problema não está no conteúdo em si mesmo, mas na forma como ele é explorado em sala de aula, sem sentido, razão pela qual "(...) muitos alunos ficam desanimados: a mensagem é de que a matemática e a ciência não são para eles: Não precisa ser assim. O problema não está nas próprias disciplinas, mas em como elas são apresentadas e ensinadas" (Resnick, 2017, p. 143, tradução nossa).

Há uma tentativa de incluir os alunos no processo de produção de significado, no qual o conhecimento não é submetido ao processo linear de definição-exemplo-exercícios, antes, porém, os alunos debatem, buscam respostas e medeiam processos de significados matemáticos quando articulam conceitos de matemática não necessariamente formais. Tal interpretação se estrutura na afirmação do aluno Eduardo: "alinhamos com os valores da base para dar mais propósito ao jogo e estimular movimentos (...) valores maiores que 1 para base $[a>1]$, porque a curva tinha que crescer $\left[x_{1}<x_{2} \Leftrightarrow \log _{a} x_{1}<\log _{a} x_{2}\right]$ ". Ao longo do processo de interpretação e construção de significados matemáticos, não se exclui uma base não formalizada matemática, mas a apreende como um fator importante no processo de construção de conhecimento e formação pela interação entre os alunos (Azevedo et al., 2018). E é justamente essa ideia que serve como alicerce "para a matemática formal, [sem] interrupção para uma melhor aprendizagem" (Papert, 2008, p. 30), na qual o processo criativo de aprendizagem se releva no discurso informal de conceitos e ideias coletivas.

A análise desse recorte se centra no discurso dos sujeitos, que combina a língua falada e a matemática, os diálogos espontâneos entre os participantes, e parte do princípio de que as ideias informais se constituem como uma "[...] oportunidade de aprender e usar a matemática através de um modo não [necessariamente] formalizado" (Papert, 2008, p. 22). Os diferentes discursos se caracterizam como engrenagens que se alimentam e se mostram interdependentes à compreensão de ideias matemáticas a partir de produção criativocoletiva. Dessa forma, reconhecemos que a construção de eletrônicos não deve se limitar ao formalismo matemático, mas oportunizar ao estudante pensar e ter um olhar amplo e problematizado (D’Ambrosio \& Lopes, 2015). Isso porque concebemos a sala de aula como espaço formativo e não de treinamento, a compreendemos como um lugar para que o 
aluno desenvolva ideias e o seu potencial criativo, e que isso possa trazer contribuições à sociedade.

A importância de "o aprendiz manipular elementos que carregam significados e que fazem sentido para ele, em vez de formalismos e símbolos” (Maltempi, 2005, p. 268) refere-se à dimensão semântica dos conceitos matemáticos (Papert, 2008; Azevedo, 2017). Compreendemos que o processo formativo do estudante em matemática, em termos dessa dimensão, não pode ser reduzido ao formalismo da robótica e da programação de jogos digitais, mas deve privilegiar o seu conhecimento prévio de modo a incentivá-lo a construir significados e estabelecer conexões de conhecimento mediante as múltiplas linguagens e simbologias. Um exemplo disso, que trazemos, nesse recorte, é a conexão mobilizada pelos alunos ativo e colaborativamente quanto à linguagem de matemática e programação gráfica.

Figura 3: Jogo Navegação: Produção coletiva da construção do algoritmo do voo do pássaro (design gráfico)

Engajamento coletivo: debate e ideias Algoritmo da função logarítmica

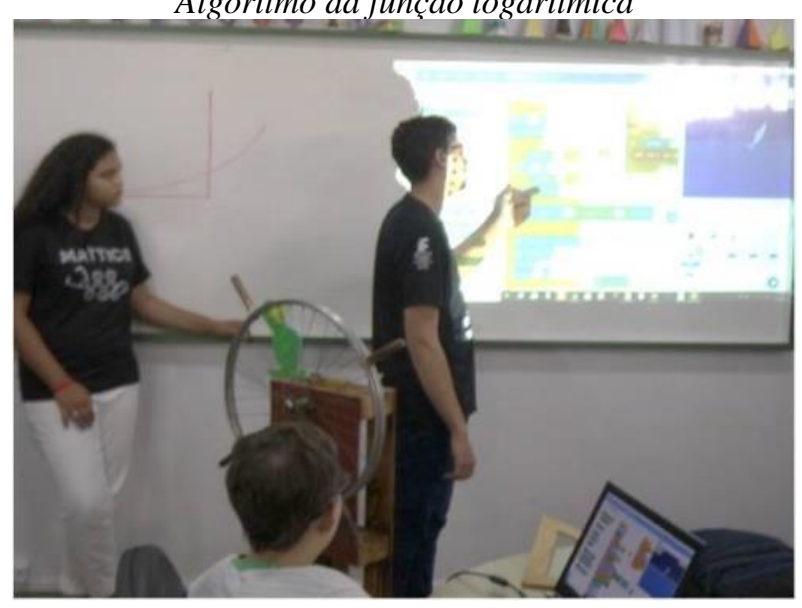

Função Logarítmica: simulação-testes e análise-comparação Simbologia: $\mathrm{f}(x)=a \pm b * \log _{c}(d *$ $x)$, sendo $a, b, c, d \in R$
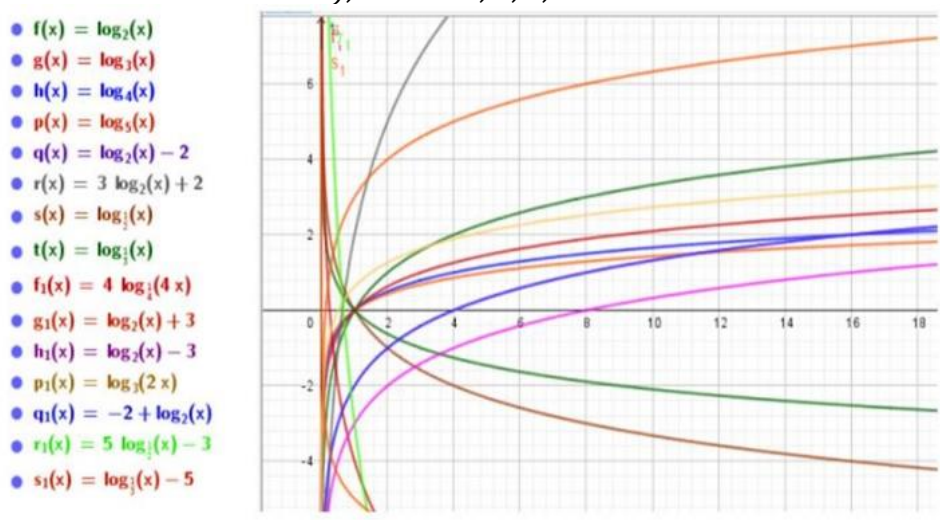

Linguagem Scratch e registros (notas dos alunos): programação e matemática (função logarítmica) 


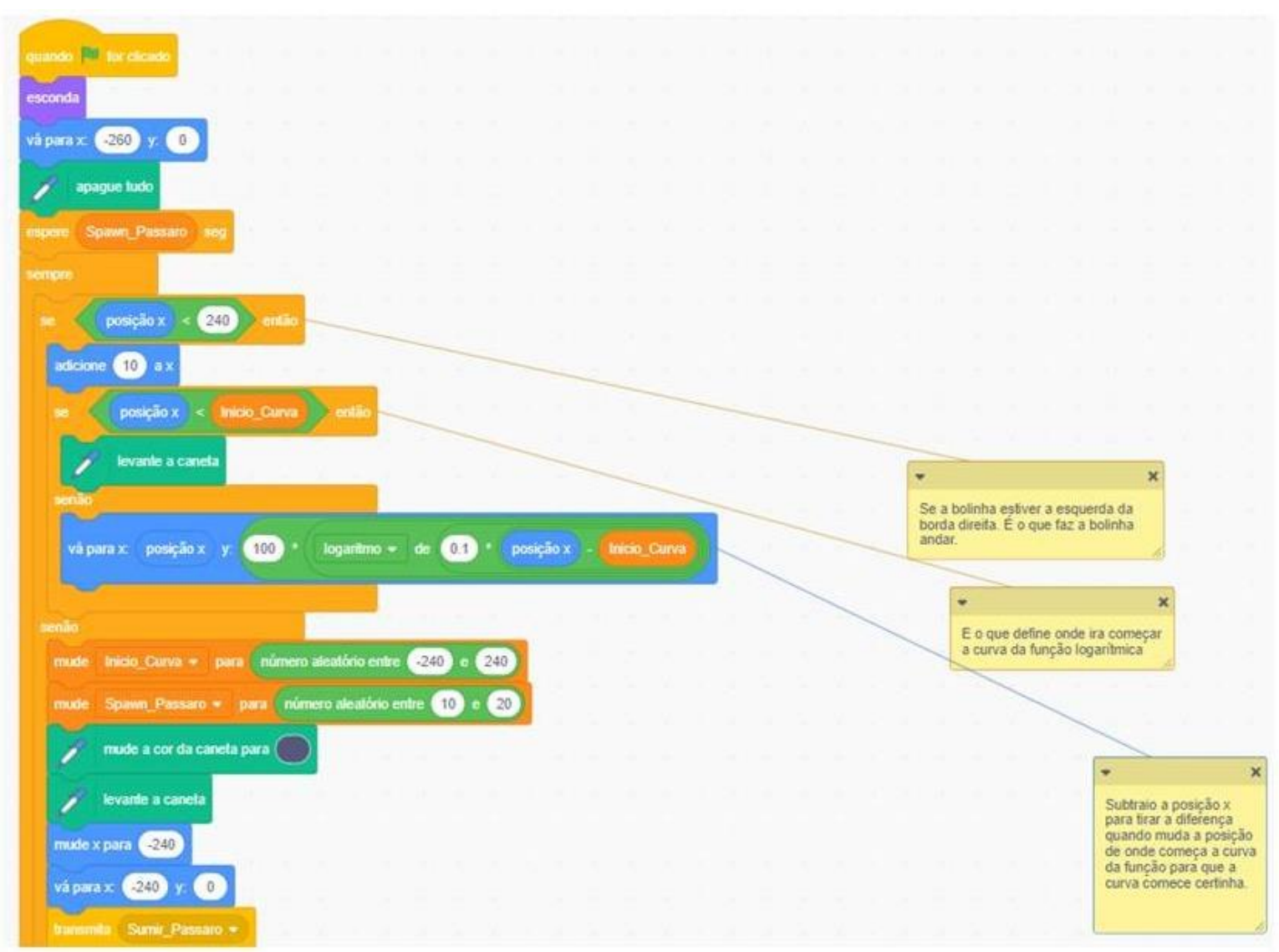

Fonte: Dados da Pesquisa (2019)

Na Figura 3, observamos o Timão-robótico ${ }^{4}$ e a produção dos algoritmos pelos alunos. Ao desenvolver os algoritmos de programação da Navegação, os alunos propuseram modelos matemáticos (como o dos movimentos do pássaro), sistematizaram ideias algébricas a partir do comportamento da função logarítmica e, por extensão, mobilizaram diferentes linguagens em suas discussões, entre as quais se destacam: oralidade, escrita, gráfica e programação. Esse contexto metodológico de aprendizagem em matemática pela produção de jogos e dispositivos robóticos, que nega a passividade e incentiva a invenção através da matemática e da programação, nos impulsiona a "superar os paradigmas previamente determinados e a busca segura em trajetórias metodológicas já percorridas" (D’Ambrosio \& Lopes, 2015, p. 8).

Mudar trajetórias nos permite a percepção de novos caminhos pedagógicos de maneira a mergulhar em espaços que estejam abertos à autonomia do aluno e a sua capacidade para inventar. Essa mudança que busca valorizar o potencial criativo e autonomia intelectual do aluno em sala significa, metaforicamente, sair da gaiola 
metodológica, o que é um ato de subversão responsável formativo (D’Ambrosio \& D'Ambrosio, 2013). Em vez de restringir o potencial criativo dos alunos, reduzindo seus talentos a uma prova, o trabalho concentra esforços para ajudar os alunos a descobrirem maneiras incríveis para aprender, comunicar ideias e a desenvolver planos de ação [como processo não linear], indo além do currículo. Um dos recortes, que nos chama a atenção na pesquisa, é o diálogo mobilizado entre os alunos na produção do jogo/timão realizado no penúltimo encontro que antecedeu a visita ao Hospital.

Figura 4: Brainstorming - Finalização das produções (ideias matemáticas e de programação)

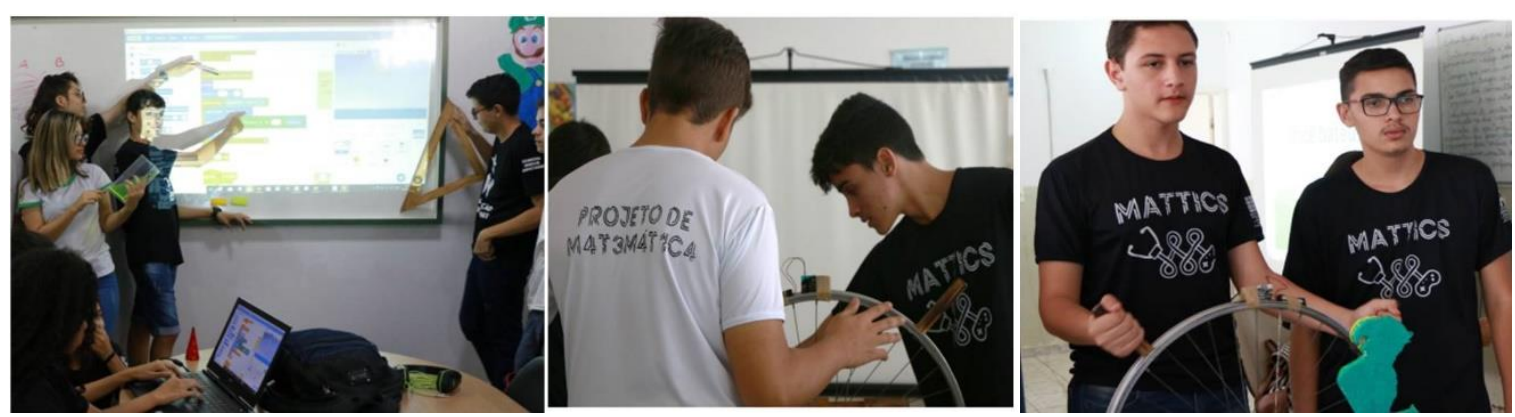

Fonte: Dados da Pesquisa (2019)

Aderson: Ao explorar a translação e dilatação da curva logarítmica, entendemos o seu comportamento a partir da manipulação dos parâmetros. Usamos inequação do $1^{\circ}$ grau [posição $\mathrm{x}<240$ ] com acréscimo de 10 a x para cada movimento dado pela curva do pássaro. Olhando assim, parece até fácil [risos]. Esse movimento logarítmico do pássaro sairá perto do leme e será captado pelo timão [mostra]. Sincronizamos o timão com o leme do navio... [Explica o algoritmo do leme].

Caio: $\quad$ Quebramos a cabeça [risos] nesse algoritmo, mas tivemos tempo para divertir, pesquisar e trocar figurinhas uns com outros [alunos e profissionais] sobre essa invenção [timão], usando paletes velhos e uma roda de bicicleta para capturar os movimentos do pacientes [...] movimento é semicircular para coluna deles.

Dani: [...] O nosso desafio maior foi o de conectar todos os algoritmos ao nosso dispositivo robótico aos movimentos rotacionais das mãos dos pacientes. Avançamos e retrocedemos várias vezes na construção de protótipos... Mas, agora, estamos ansiosos para usar tudo que criamos nesse tempo para ajudalos [os pacientes]. É incrível aplicar isso à sessão de terapia de Parkinson (...)

Na Figura 4, à luz do diálogo, observamos que o processo criativo de aprendizagem percorre os desafios de pensar, inventar e compartilhar, como se denotam nas expressões dos estudantes, Aderson e Caio: “(...) olhando assim, parece até fácil” [e] "quebramos a cabeça [...] tivemos tempo para divertir, pesquisar e trocar figurinhas uns com outros”. Não se nega a motivação ou o prazer de fazer aquilo com a matemática em sala de aula, mesmo quando há desafios constantes, caminhos imprevisíveis e situações-problema sem respostas ao longo do percurso de criação de objetos tecnológicos. Isto é, "quando os alunos têm 
mais opções e controle, eles podem desenvolver seus interesses e paixões, e o aprendizado se torna mais pessoal, criativo, motivador e mais significativo" (Resnick, 2017, p. 78, tradução nossa).

Os alunos imergem em processos de aprendizagem não previsíveis no qual investigam problemas e por meio deles mobilizam conhecimentos e propõem possíveis soluções para uma finalidade maior - desenvolvem objetos científico-tecnológicos a favor das pessoas. Notamos que o conteúdo matemático não se mostra ilhado e nem se fragmenta em departamentos ao ser explorado ao longo da construção dos objetos do jogo e da produção do dispositivo robótico. Pelo contrário, os alunos exploram ideias de programação e matemática de forma integrada como: laços de repetição e ideias condicionais relacionados às estruturas algébricas [funções e equações], plotação geométrica [gráficos], aprendem novas ideias, habilidades e estratégias enquanto trabalham em projetos pessoais significativos nos campos científico e social. À medida que “(...) os alunos constroem coisas no mundo, eles constroem novas ideias em suas cabeças, o que os motiva a construir coisas novas no mundo, e assim por diante, de uma maneira nunca vista, em espiral de aprendizagem" (Resnick, 2017, p. 38, tradução nossa).

O processo criativo de matemática em sala de aula é, portanto, empreendido como a capacidade de construir o novo de forma útil para o outro, bem como para si mesmo. Nesse sentido, compreendemos que o processo criativo de aprendizagem em matemática, a partir da produção jogo Navegação e do dispositivo Timão, à luz das ideias da Aprendizagem Criativa (Resnick, 2017; Papert, 2008; Azevedo et al., 2018; Azevedo \& Maltempi, 2019) e da Insubordinação Criativa (D'Ambrosio \& Lopes, 2015; D’Ambrosio \& D'Ambrosio, 2013), se mostra caracterizado pela imaginação e originalidade de ideias coletivas. Apresenta-se pela discussão-produção-argumentação e produção de artefatos curiosos, que não obedecem a uma lógica linear e obrigatória de passos prefixados ou procedimentos repetitivos sem significados.

No que se refere à construção de ideias matemáticas como um processo não linear de etapas, destacamos a fala da estudante Dani, que nos ajuda a entender esse contexto: “(...) avançamos e retrocedemos várias vezes na construção de protótipos (...) à sessão de terapia de Parkinson”. Não há uma sequência necessariamente de única mão e absolutista, na verdade, o processo de produzir criativamente nas aulas de matemática é uma proposta que impulsiona diferentes experiências de idas e vindas de ações "mão na massa", pautando-se pela insubordinação ao treino do conteúdo e da aprendizagem sem sentido e 
atrevendo-se a atribuir significados ao conhecimento matemática pela invenção de eletrônicos aos pacientes.

\section{Discussão dos resultados à luz dos pressupostos teóricos da pesquisa}

O jogo Navegação foi idealizado e desenvolvido por alunos, em sala de aula, com o suporte de um time de profissionais da educação, computação e área médica, com o objetivo de ajudar no tratamento da doença de Parkinson. Compreendemos esse processo como uma insubordinação criativa, diante dos processos meramente burocráticos da educação básica e atrevemo-nos “(...) a criar e ousar nas práticas exitosas como um desejo de promover uma aprendizagem na qual os estudantes atribuam significados ao conhecimento matemático" (D’Ambrosio \& Lopes, 2015, p. 2). Ao produzir jogos e dispositivos de robótica nas aulas de matemática, buscamos preparar os alunos para além dos testes e exames muito comuns atualmente, inserindo-os em um ambiente de invenção científico-tecnológica. Nessa perspectiva, o processo criativo de matemática é entendido como uma construção intelectualmente coletiva e socialmente engajada, que não nega os conteúdos curriculares de matemática no ambiente de formação, e se mostra pela contextualidade e problematização dos conhecimentos, favorecendo experiências orgânicas, processuais e dialógicas às demandas da sociedade (D'Ambrosio \& Lopes, 2015).

Desta forma, o processo criativo de matemática a partir da produção de eletrônicos busca privilegiar as características do saber e fazer matemática, entre as quais se destacam: propor ideias e soluções (Papert, 2008), compreender e explorar conhecimentos integrados em contextos reais e inusitados de aprendizagem (Azevedo, 2017); reconhecer erros matemáticos e de programação e robótica e saber depurá-los a partir de diferentes estratégias (Maltempi, 2012); desenvolver ideias e ferramentas a problemas reais (D’Ambrosio \& Lopes, 2015); lidar com imprevistos e questões inusitadas (Resnick, 2017); usar modelos matemáticos para promover o bem-comum em sociedade, usando materiais de baixo custo (Azevedo et al., 2019).

Ao explorar modelos matemáticos, estabelecer novas relações do conteúdo e desenvolver projetos de interesse pessoal, os alunos têm a oportunidade de mobilizar conhecimentos prévios e construir conhecimentos algébricos e geométricos específicos, em sala de aula. Nesse sentido, "[...] o processo de se tornar um pensador Criativo "com C maiúsculo" é em si um processo interativo" (Resnick, 2017, p. 5, tradução nossa), que 
conjuga elementos de formação. Por isso, acreditamos que há um equívoco comum de que a melhor maneira de incentivar a criatividade dos alunos é "(...) apenas sair do caminho e deixá-los serem criativos. Embora seja certamente verdade que os alunos são naturalmente curiosos, eles precisam de apoio para desenvolver suas capacidades criativas e alcançar seu potencial criativo total” (Resnick, 2017, p. 167, tradução nossa) e poder usar a sua capacidade de produzir conhecimentos e inventar coisas úteis e científico-tecnológicas a favor da sociedade.

A pesquisa nos levou a constatar que, em vez de definição-exemplo-respostas, em sala de aula, as situações-problema de aprendizagem buscaram valorizar a compreensãoinvenção-resultados ao tratamento de sintomas da doença de Parkinson (Azevedo et al., 2019), dialogando com a Educação para o Futuro ${ }^{5}$, indo além de um teste classificatório.

Figura 5: Sessão de tratamento da doença de Parkinson

\section{SESSÃO 1: Tratamento de Parkinson}

Movimentos coordenados e estratégicos orientados por profissional da área da saúde

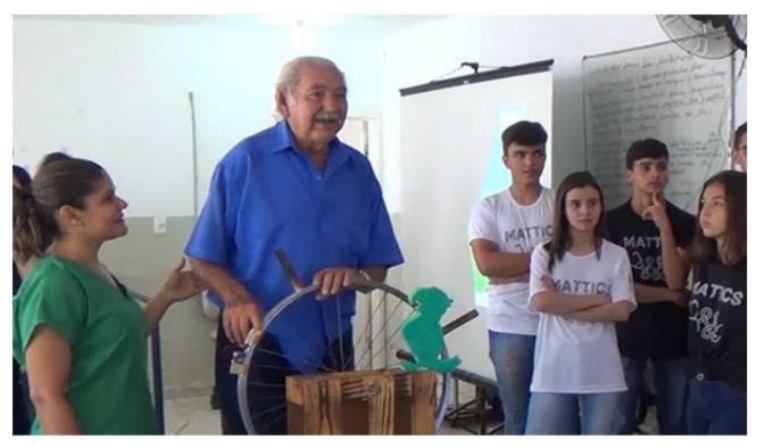

SESSÃO 2: Tratamento de Parkinson

Contribuições dos alunos na preparação dos equipamentos e instrução dos jogos e do dispositivo-robótico (Timão)

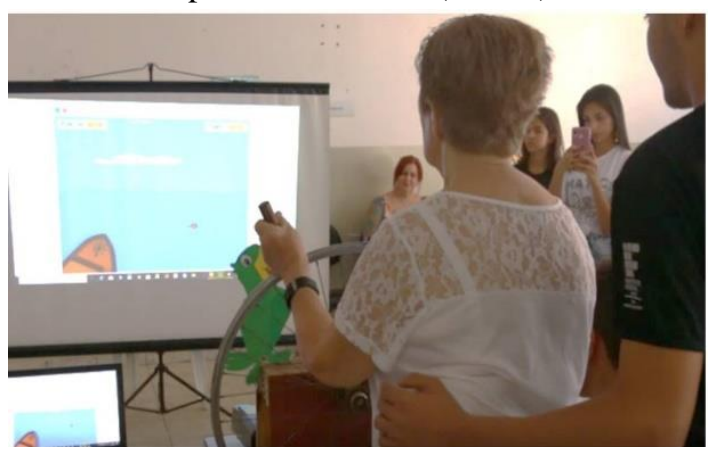

Fonte: Dados da Pesquisa (2019)

Na Figura 5 vemos o jogo e o dispositivo robótico sendo mediados pelos profissionais da área da saúde e educação, além do apoio dos alunos, na sessão de tratamento de sintomas da doença de Parkinson. As visitas mensais ao hospital se constituem como insubordinação criativa ao sistema educacional, que visa preparar os alunos não só às provas, mas à vida e aos processos científicos e criativos. Nessa perspectiva, entendemos que o conhecimento científico mobilizado nas aulas de matemática se organiza em "uma complexidade educativa, a qual requer que se levem em conta perplexidades e contradições reais das instituições educacionais" (D'Ambrosio \& Lopes, 2015, p. 5). 
Além disso, de acordo com Bruna Cândito, profissional da área da saúde do hospital e integrante voluntária do projeto, os eletrônicos produzidos pelos alunos têm contribuído no tratamento de reabilitação de movimentos estratégicos dos grupos de dezenas de pacientes (em especial, idosos), ajudando-os na movimentação estratégica das mãos e incentivando-os a ter a postura adequada da coluna, além de possibilitar a redução de tremores simétricos e rigidez, estímulos esses que podem melhorar a qualidade de vida dos pacientes (Moreira et al., 2007).

É uma iniciativa que se amálgama às ideias defendidas pela Organização Mundial da Saúde (OMS), que objetiva incentivar o "Envelhecimento Ativo", que busca estimular espaços para o desenvolvimento físico, motivacional e o bem-estar da saúde mental dos idosos. Nesse contexto, o espaço formativo de sala de aula vai além do conteúdo matemático e contribui para "reflexões necessárias para realizar o objetivo maior da Educação que é o preparo humano para participar na criação de um mundo melhor" (D’Ambrosio \& D'Ambrosio, 2013, p. 10) e mais responsável e atual, possibilitando a constituição "de uma [formação matemática] pautada em princípios éticos, e solidários" (Lopes \& D’Ambrosio, 2015, p. 14).

O trabalho é sempre voltado para os desafios emergentes da sociedade brasileira e, por extensão, com impacto da comunidade local, que reflete em boas ações, respeito e senso de humanidade. Ao interagir responsavelmente com diferentes profissionais e estudantes, os alunos aprendem a: ser solidários; lidar com as frustrações, medo e egoísmo; enfim vencer os desafios da vida. Conforme Amanda Rodrigues, aluna participante do projeto, “(...) muito além de estimular a nossa capacidade intelectual e o nosso potencial criativo nas aulas de matemática, quando produzimos nossos controles e robôs, é a de proporcionar experiências marcantes de impacto formativo, científico e humano ao tratamento de pacientes idosos".

\section{Considerações Finais}

Ao longo da produção do jogo e dispositivo robótico, compreendemos que o processo criativo da aprendizagem de matemática se mostra dinâmico, fluído e se configura na produção de sentidos pelos alunos, dos conceitos matemáticos e das ideias de programação, resgatando elementos inerentes ao processo humano, entre os quais se destacam: curiosidade, inquietação, argumentação, intuição-lógica e hipóteses, erros e depurações, além dos avanços e retrocessos. Por meio de processos de pesquisa e diálogo, 
os alunos passaram da posição de receptores de informações e repetidores de conteúdos à posição de protagonistas de seu processo de formação e criação, privilegiando aspectos do pensamento lógico-dedutivo e criativo-exploratório. O processo criativo de aprendizagem em matemática provoca aspectos da insubordinação às práticas mecânicas e do foco excessivo aos testes escalonáveis. Assim, cabe-nos refletir sobre uma formação matemática que não se encerre no conteúdo curricular e que nos permita ampliar nossas visões acerca da aprendizagem e visões sobre o mundo. Com isso, retomamos a fala de Ubiratan D’Ambrosio (2013), que nos impulsiona a vislumbrar contextos atuais de formação e nos provoca a pensar em aspectos científicos à matemática.

Isso porque, ao longo do processo de aprendizagem criativa de matemática, os alunos se mostram preparados para uma sociedade futura e intelectualmente científica, tecnológica e solidária, de tal modo que sejam capazes de interpretar e visualizar situações reais, tomar decisões, lidar com imprevistos, bem como construir/propor possíveis soluções para problemas reais a partir da matemática e suas tecnologias a favor da sociedade, de modo que as carreiras científicas e tecnológicas sejam um de seus possíveis projetos de vida e transformação social e intelectual. O conteúdo de Matemática previsto no currículo básico do ensino médio (em todo território nacional) é explorado/investigado e aplicado durante a construção de algoritmos dos jogos e da parte de robótica, usando materiais de baixo custo.

Cabe-nos também evidenciar que a produção de jogos digitais e dispositivos robóticos nas aulas de matemática se dá pelo uso de materiais de baixo custo, que privilegia aspectos de reciclagem e da consciência ambiental nos moldes de uma sociedade mais sustentável. Negamos a compra de materiais que não dialoga com a maior parte das realidades das escolas públicas e não aquecemos o mundo das empresas de robótica, mesmo quando reconhecemos as possíveis potencialidades que elas podem proporcionar, como: Mindstorms LEGO Kid.

O processo criativo de aprendizagem tem objetivo final prático: os jogos são usados para o tratamento de idosos diagnosticados com a doença de Parkinson. Assim, entendemos a sala de aula como ambiente de formação de criatividade, capacidade cognitiva, cooperação mútua e desenvolvimento de senso de responsabilidade social. A proposta de ensino de matemática vai ao encontro à tendência mundial da construção de jogos e produção de robôs (Resnick, 2017). Isso porque, não construímos jogos ou dispositivos robóticos para competição entre crianças e jovens. Pelo contrário, tais 
dispositivos eletrônicos têm um propósito maior que, além de incentivar o espírito de colaboração e pesquisa, é o de beneficiar dezenas de pacientes com a doença de Parkinson, usando invenções criativas e materiais de baixo custo à luz dos conhecimentos científicotecnológicos de matemática. A ideia não é de vencer ou perder como em um jogo qualquer ou de montar um circuito de robôs para tirar da arena de competição; mas sim, é a de estimular uma comunidade inteira de jovens pela aprendizagem e invenção da matemática voltada para a competição maior - que é a de criar coletivamente soluções para um mundo melhor, mais solidário e intelectualmente engajado.

\section{Agradecimentos}

Aos queridos alunos do Ensino Médio do IF IF-Goiano, Ipameri - GO, pela dedicação contínua no Projeto Mattics, e também aos incríveis profissionais que sonham de perto essas invenções. Aos pacientes do Hospital Dia do Idoso, Anápolis - GO, vocês são inspiradores. Agradecemos também a querida Profa. Dra. Maria Luiza Batista pelas contribuições no texto. O segundo autor é apoiado pela FAPESP (Processo 2018/14053-2) e CNPq (Processo 308563/2019-0).

\section{Referências}

Azevedo, G. T. de (2017). Construção de conhecimento matemático a partir da produção de jogos digitais em um ambiente construcionista de aprendizagem: possibilidades e desafios. Dissertação (Mestrado em Educação em Ciências e Matemática) Instituto de Matemática e Estatística. Universidade Federal de Goiás. Goiânia.

Azevedo, G. T., Maltempi, M. V. \& Lyra-Silva, G. G. M. V. (2018). Processo formativo do aluno em matemática: jogos digitais e tratamento de Parkinson. Zetetike, 26(3), 569-585. https://doi.org/10.20396/zet.v26i3.8651962

Azevedo, G. T., Maltempi, M. V. \& Lyra, G. M. V (2019). Computacional thinking and Active Learning in Mathematics as a contribution to the treatment of Parkinson's disease. In: Science and mathematics education in the 21 st century (pp. 75-76). Universidade do Minho.

Azevedo, G. T.; Maltempi, M. V.; Lyra, G. M. V. \& Ribeiro, J. P. M (2018). Produção de games nas aulas de Matemática: por que não? Acta Scientiae, Canoas, 20, 950-966. https://doi.org/10.17648/acta.scientiae.v20iss5id4152

Bicudo, M. A. V (2006). Pesquisa qualitativa e pesquisa qualitativa segundo a abordagem fenomenológica. In: M. de C. Borba, J. de L. Araújo (Org.). Pesquisa qualitativa em Educação Matemática (pp. 100-118). Autêntica.

Bogdan, R. C. \& Biklen, S. K (1994). Investigação qualitativa em Educação. Tradução Maria João Alvarez, Sara Bahia dos Santos e Telmo Mourinho Baptista. Porto Editora. 
D'Ambrosio, U. \& D'Ambrosio, B. S. (2013). The role of ethnomathematics in curricular leadership in mathematics education. Journal of Mathematics Education at $\begin{array}{lll}\text { Teachers } & \text { College, } & \text { 10-16. }\end{array}$ https://journals.library.columbia.edu/index.php/jmetc/article/view/767

D’Ambrosio, B. S. \& Lopes, C. E. (2015). Insubordinação Criativa: um convite à reinvenção do educador matemático. Revista Bolema, Rio Claro (SP), 29(51), 1-17. https://www.scielo.br/scielo.php?pid=S0103636X2015000100002\&script $=$ sci_abstract\&tlng $=\mathrm{pt}$

Freire, P. (2005). Pedagogia da autonomia - saberes necessários à prática educativa. 31 ed. Paz e Terra.

Gontijo, C. H. (2007). Criatividade em Matemática um olhar sob a perspectiva de Sistemas. Zetetiké, 15(28), 153-172. https://periodicos.sbu.unicamp.br/ojs/index.php/zetetike/article/view/8647029

Maltempi, M. V (2012). Construcionismo: pano de fundo para pesquisas em informática aplicada à Educação Matemática. In: M. A. V. Bicudo e M. de C. Borba, (Org.). Educação Matemática: pesquisa em movimento (pp. 287-307). Cortez.

Maltempi, M. V. (2005). Novas tecnologias e construção de conhecimento: reflexões e perspectivas. Em: Actas do $V$ Congresso Ibero-Americano de Educação Matemática (V CIBEM) (pp. 1-11). Associação de Professores de Matemática.

Moreira, C. S.; Martins, K. F. C.; Neri, V. C. \& Araújo, P. G (2007). Doença de Parkinson: como diagnosticar e tratar. Revista Científica da Faculdade de Medicina de Campos, 2(2), p. 19-29.

Nakamura, J. \& Csikszentmihalyi, M. (2003). Creativity in later life. In: R. K. Sawyer (Org.), Creativity and development (pp. 186-216). Oxford University Press.

Papert, S. (2008) A máquina das crianças: repensando a escola na era informática. Tradução de Sandra Costa. Artes Médicas.

Resnick, M. (2017). Lifelong Kindergarten: cultivating creativity through projects, passion, peers and play. MIT Press.

Triviños, A. N. S. (2009). Introdução à pesquisa em Ciências Sociais: a pesquisa qualitativa em Educação. 18 reimpressão. Atlas.

\section{Autores}

Greiton Toledo de Azevedo

Matemático e especialista em Educação Matemática com ênfase em Matemática Computacional pelo Instituto de Matemática e Estatística da Universidade Federal de Goiás (IME/UFG). Mestre em Educação em Ciências e Matemática pela UFG. Doutorando em Educação Matemática pela UNESP. Professor efetivo do Instituto Federal Goiano (IF-

Goiano). Temas de Pesquisa: Tecnologias na Educação; Educação Matemática e Matemática Computacional. E-mail: greiton.azevedo@ifgoiano.edu.br

Marcus Vinicius Maltempi

Doutor em Engenharia Elétrica e de Computação pela Unicamp. Pós-doutorado na Universidade de Londres (Inglaterra). Livre-docente em Educação Matemática pela Unesp. Professor Associado da Unesp de Rio Claro. Temas de pesquisa: Tecnologias na Educação, Educação Matemática e Educação a Distância. E-mail: marcus.maltempi@unesp.br 